\title{
Sodium orthovanadate induces the apoptosis of SH-SY5Y cells by inhibiting PIWIL2
}

\author{
XIAOHONG TIAN, JUN FAN, WEIJIAN HOU, SHULING BAI, QIANG AO and HAO TONG \\ Department of Tissue Engineering, School of Fundamental Science, \\ China Medical University, Shenyang, Liaoning 110122, P.R. China
}

Received January 20, 2015; Accepted November 6, 2015

DOI: $10.3892 / \mathrm{mmr} .2015 .4616$

\begin{abstract}
PIWIs have been shown to be abnormally expressed in a variety of cancers and may be important in the maintenance and invasion of cancer cells. The high expression of PIWIL2 contributed to the resistance effect of cisplatin in colon cancer cells, and the knockout of the PIWIL2 gene reduced the aggressive nature and malignant degree of colon cancer cells. Sodium orthovanadate (SOV) is a vanadium compound, and exhibited antineoplastic activity in certain types of human cancer cells, including lung, kidney and prostate cancer cells. However, its effects in human neuroblastoma (NB) cells have not yet been reported. The objective of this study was to investigate the effect of SOV on the apoptosis of NB cells and to explore how PIWIL2 is involved in the mechanism underlying this effect. In the present study, SH-SY5Y cells were treated with SOV and the optimal concentration was determined for further assays. Cell apoptosis, cell count, viability, the cell cycle, and the expression of PIWIL2 mRNA and protein were then determined. The results showed that SOV could induce cell apoptosis, reduce the percentage of viable cells, induce accumulation of SH-SY5Y cells at the G2/M and S phase of the cell cycle, and inhibit the expression of PIWIL2 and Bcl-2 mRNA and protein. The results suggested that the underlying mechanisms may be, at least in part, due to SOV inhibiting the expression of PIWIL2. These findings demonstrated the effect of SOV and supported its further evaluation as a treatment for human NB.
\end{abstract}

Correspondence to: Professor Shuling Bai, Department of Tissue Engineering, School of Fundamental Science, China Medical University, 77 Puhe Road, Shenyang North New Area, Shenyang, Liaoning 110122, P.R. China

E-mail: shuling_bai@126.com

Key words: sodium orthovanadate, PIWIL2, neuroblastoma, apoptosis

\section{Introduction}

Neuroblastoma (NB) is the most common type of extra-cranial malignant tumor in childhood and infancy, and accounts for $8-10 \%$ of all childhood cancers and for $\sim 15 \%$ of infant cancer-related mortality (1-3). The current treatment strategies include high-dose chemotherapy with autologous stem cell transplantation, radiation and surgery. Even with this aggressive treatment, $<40 \%$ of children are likely to achieve a long-term cure (4-6). As a result, the patients usually experience tumor recurrence as well as long-term complications following high-dose chemotherapy $(7,8)$. Therefore, identification of more effective and less toxic therapies, and molecular target-directed drugs is urgently required.

PIWI proteins are members of the Argonaute family, and the human PIWI subfamily genes encode four PIWI proteins (also known as PIWI-like proteins): PIWIL1 (HIWI, piwi homology), PIWIL2 (HILI, CT80, PIWIL1L, Miwi like, and Mili in mouse), PIWIL3 (HIWI3), and PIWIL4 (HIWI2, MIWI2) (9). Although the biological function of PIWI proteins during tumorigenesis remains unclear, it has been reported that PIWIs are critical in germline and hematopoietic stem cell self-renewal, spermatogenesis, translational regulation and chromatin remodeling (10-12). In addition, PIWIs were abnormally expressed in a variety of cancers and may be important in the maintenance and invasion of cancer cells $(13,14)$. Among them, the high expression of PIWIL2 contributed to the resistance effect of cisplatin drugs in colon cancer cells (15), and the knockout of the PIWIL2 gene reduced the aggressive and malignant degree of colon cancer cells (16). However, the above functions of PIWIL2 in NB cells remain unclear.

As a vanadium compound, sodium orthovanadate (SOV; molecular formula, $\mathrm{NO}_{3} \mathrm{VO}_{4}$ ) has a number of biological activities, including the inhibition of nonselective protein tyrosine phosphatases, activation of tyrosine kinases, mitogenic, neuroprotective and antidiabetic effects $(17,18)$. In addition, SOV was also used as an inhibitor of the piRNA-PIWI signal pathway in Drosophila (19). A recent study has also demonstrated that it exhibited antineoplastic activity in certain types of human cancer cells, including lung, kidney and prostate cancer (20), but the effects of SOV in human NB cells have not yet been reported.

In this study, the anti-proliferative effect of SOV on the human NB cell lines was investigated. The effect of SOV on 
cell apoptosis was also observed and the role of PIWIL2 in this effect was investigated.

\section{Materials and methods}

Cell culture and the PIWIL2 inhibitor. Human NB SH-SY5Y cells were obtained from the American Type Culture Collection (Rockville, MA, USA), and cultured in Dulbecco's modified Eagle's medium (DMEM; Hyclone, Logan, UT, USA), with $10 \%$ fetal bovine serum (FBS; Gibco, Thermo Fisher Scientific Inc., Waltham MA, USA) and $1 \%$ penicillin/streptomycin (Sigma-Aldrich, St. Louis, MO, USA), and were grown in a $5 \% \mathrm{CO}_{2}$ incubator at $37^{\circ} \mathrm{C}$. The PIWIL2 inhibitor SOV was purchased from Sigma-Aldrich.

Cell viability assay. Cell viability was assessed by an MTT assay. Briefly, SH-SY5Y cells were seeded in a 96-well culture plate, and subsequently treated with different concentrations of SOV for 24, 48 or $72 \mathrm{~h}$. Control cells were treated with phosphate-buffered saline (PBS) in culture medium. Following treatment, the cells were incubated with $20 \mu \mathrm{l}$ MTT reagent ( $5 \mathrm{mg} / \mathrm{ml}$; Sigma-Aldrich) for $4 \mathrm{~h}$. MTT was then removed and $150 \mu \mathrm{l}$ dimethyl sulfoxide was added, cells were then analyzed by colorimetric analysis using a multi-label plate reader (Bio-Rad, Hercules, CA, USA) at $490 \mathrm{~nm}$. Experiments were conducted in triplicate, average activity rates were relative to control and standard error was calculated.

Apoptosis assays. The Annexin V/fluorescein isothiocyanate (FITC) Apoptosis Detection kit (KeyGEN Biotech, Nanjing, China) was used for measuring apoptosis according to the manufacturer's protocol. Firstly, equal numbers of SH-SY5Y cells treated with PBS or SOV for 24,48 or $72 \mathrm{~h}$, were incubated with Annexin V-FITC, followed by staining of their DNA with propidium iodide (PI; Sigma-Aldrich) in the dark. Then, each sample was analyzed by fluorescence-activated cell sorting (FACSAria II; BD Biosciences, San Jose, CA, USA). The percentages of cells stained positive for Annexin V were calculated, and the means as well as the standard error were plotted.

Count and viability testing. The quantitative analysis of cell count and viability were determined using the Muse Count \& Viability kit (MCH100102; Merck KGaA, Darmstadt, Germany) on the Muse Cell Analyzer (EMD Millipore, Billerica, MA, USA). The Muse Count \& Viability Reagent differentially stains viable and non-viable cells based on their permeability to the two DNA binding dyes present in the reagent. First, equal numbers of SH-SY5Y cells were treated with PBS or SOV for 24,48 or $72 \mathrm{~h}$. Then a uniform cell suspension was prepared with the cell concentrations adjusted in the range of $1 \times 10^{5}-1 \times 10^{7}$ cells $/ \mathrm{ml}$. Stained cell samples were then prepared by mixing cells with Muse Count \& Viability Reagent in a sample tube. Subsequently the cells were left to take up the stain for a minimum of $5 \mathrm{~min}$. The samples were then detected on Muse Cell Analyzer according to the manufacturer's protocol. The Muse Count \& Viability Software Module (EMD Millipore) was then used to perform calculations automatically and display data in two dot plots.
Cell cycle analysis. Equal numbers of SH-SY5Y cells were plated in 10-cm dishes and treated with PBS or SOV for 24, 48 or $72 \mathrm{~h}$. In total, $10^{6}$ cells were trypsinized (Sigma-Aldrich), fixed with $70 \%$ ethanol and incubated overnight at $4^{\circ} \mathrm{C}$. Cells were then incubated in $100 \mu \mathrm{l}$ RNase (Merck Millipore, Darmstadt, Germany) at $37^{\circ} \mathrm{C}$ for $30 \mathrm{~min}$, followed by staining of the DNA with $400 \mu \mathrm{l}$ PI for $30 \mathrm{~min}$ in the dark, and FACS analysis. The average percentages of cells in G0/G1, S or G2/M phases of the cell cycle were quantified and standard error was calculated for three experiments.

Reverse transcription-quantitative polymerase chain reaction $(R T-q P C R)$ analysis. Total RNA was extracted using the RNeasy Mini kit (Qiagen, Valencia, CA, USA) and quantified using NanoDrop 1000 (NanoDrop, Wilmington, DE, USA). Then the RNA was reverse transcribed into cDNA using PrimeScript RT reagent kit with gDNA Eraser (Takara Bio Inc., Otsu, Japan). RT-qPCR was performed using SYBR Premix Ex Taq ${ }^{\text {TM }}$ II (Takara Bio Inc.) on a ABI 7500 Real-Time PCR system (Applied Biosystems, Thermo Fisher Scientific Inc.). A total of $520 \mathrm{ng}$ of cDNA was obtained. The following primer sequences were used: Forward: 5'-CGGAATGACTGT GTGCTGGA-3 and reverse: 5'-GGTGATAACAATATTGCC AACCAGA-3' for human PIWIL2; and forward: 5'-TGGCAC CCAGCACAATGAA-3' and reverse: 5'-CTAAGTCATAGT CCGCCTAGAAGCA-3' for human $\beta$-actin. Primers were obtained from Takara Biotechnology Co., Ltd. (Dalian China) The PCR amplification was conducted under the following conditions: $95^{\circ} \mathrm{C}$ for $30 \mathrm{sec} ; 95^{\circ} \mathrm{C}$ for $5 \mathrm{sec}$, and $60^{\circ} \mathrm{C}$ for $34 \mathrm{sec}$ for 40 cycles. The relative changes in gene expression data were analyzed by the $2^{-\Delta \Delta \mathrm{Ct}}$ method. $\beta$-actin was used as an internal control. Triplicates were run for each sample in three independent experiments.

Western blot analysis. Equal numbers of SH-SY5Y cells were plated on $10-\mathrm{cm}$ plates and treated with PBS or SOV for 24, 48 or $72 \mathrm{~h}$. Then the cells were lysed with radioimmunoprecipitation assay buffer (Beyotime Institute of Biotechnology, Shanghai, China) and protein concentration was determined by the Bradford method using a Bicinchoninic Acid Protein Assay kit (cat. no. P0012; Beyotime Institute of Biotechnology) $(21,22)$. Equal amounts of protein $(40 \mu \mathrm{g})$ were separated by sodium dodecyl sufate polyacrylamide gel electrophoresis and then transferred onto polyvinylidine difluoride membranes (EMD Millipore). The blotted membranes were blocked with $5 \%$ non-fat dry milk $(w / v)$ in Tris-buffered saline with $0.1 \%$ Tween 20 , and then incubated at $4^{\circ} \mathrm{C}$ overnight with rabbit monoclonal anti-PIWIL2 (Bioss Inc., Woburn, MA, USA; cat. no. bs-3817R) and anti-Bcl-2 (Santa Cruz Biotechnology Inc., Santa Cruz, CA, USA; cat. no. sc-492) antibodies. Specific antibody binding was detected using polyclonal horseradish peroxidase-conjugated goat anti-rabbit antibodies (cat. no. A0208; Beyotime Institute of Biotechnloogy; 1:1,000) and visualized with an enhanced chemiluminescence reagent (cat. no. sc-2048; Santa Cruz Biotechnology Inc.), according to the manufacturer's protocol. Goat polyclonal IgG antibodies against $\beta$-actin (cat. no. sc-1616; Santa Cruz Biotechnology, Inc.; 1:200) was used to evaluate protein loading in each lane. Quantification was performed using Image J software 


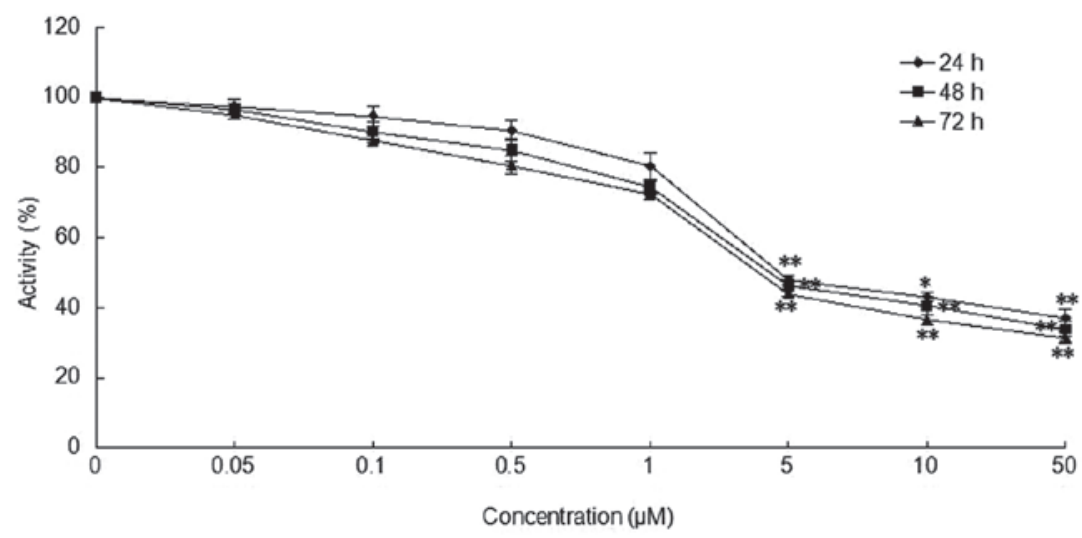

Figure 1. Cellular activity of SH-SY5Y cells after SOV treatment at 24,48 and $72 \mathrm{~h}$ with different concentrations of SOV. ${ }^{*} \mathrm{P}<0.05,{ }^{* *} \mathrm{P}<0.01$. SOV, sodium orthovanadate $\left(\mathrm{Na}_{3} \mathrm{VO}_{4}\right)$.

A
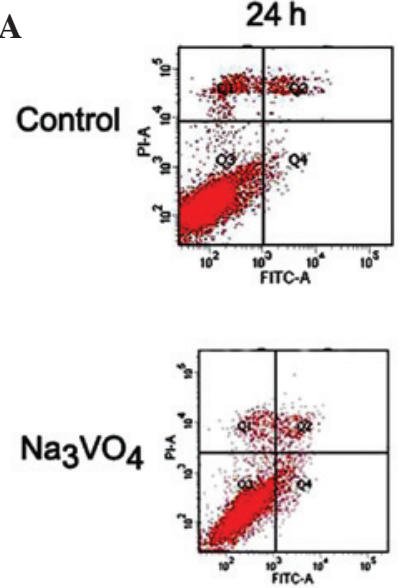

B
$48 \mathrm{~h}$
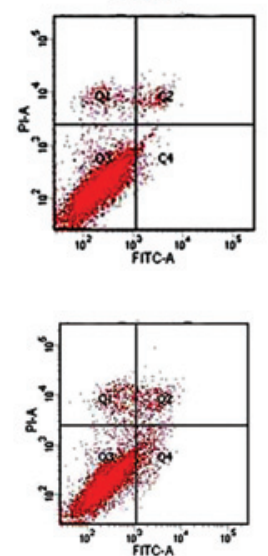

$72 \mathrm{~h}$
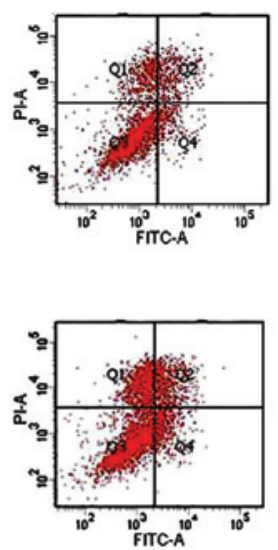

**
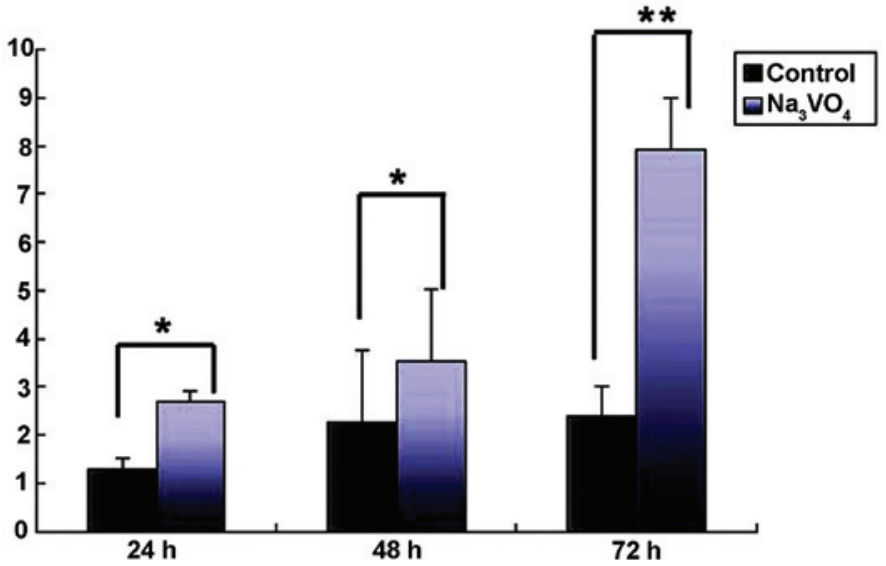

Figure 2. SOV induces cell apoptosis in SH-SY5Y cells. (A) SH-SY5Y cells stained with Annexin V in the control group and SOV group. (B) Bar graph of the average percentage of apoptotic cells in the control and SOV groups. ${ }^{*} \mathrm{P}<0.05$ and ${ }^{* *} \mathrm{P}<0.01$ vs. control. SOV, sodium orthovanadate $\left(\mathrm{Na}_{3} \mathrm{VO}_{4}\right)$; FITC, fluorescein isothiocyanate.

version 1.44 (National Institutes of Health, Bethesda, MA, USA)

Statistical analysis. Each experiment was repeated three times. All quantitative variables were analyzed using one way analysis of variance followed by Tukey's post-hoc test using SPSS software, version 16.0 (SPSS, Inc., Chicago, IL, USA). The results are presented as the mean \pm standard deviation, and the standard deviation were presented as error bars in the figures. $\mathrm{P}<0.05$ was considered to indicate a statistically significant difference.

\section{Results}

SOV decreases cell growth and proliferation in SH-SY5Y cells. SOV has been described as a potent small molecule inhibitor of PIWIL2 and could induce cell apoptosis and inhibit autophagy in human hepatocellular carcinoma (HCC) cells, in vitro and in vivo (18). To elucidate the role of SOV in NB, it was investigated how different concentrations of SOV affect cell proliferation in SH-SY5Y cells with different concentrations. SH-SY5Y cells showed reduction in cell proliferation after 
A
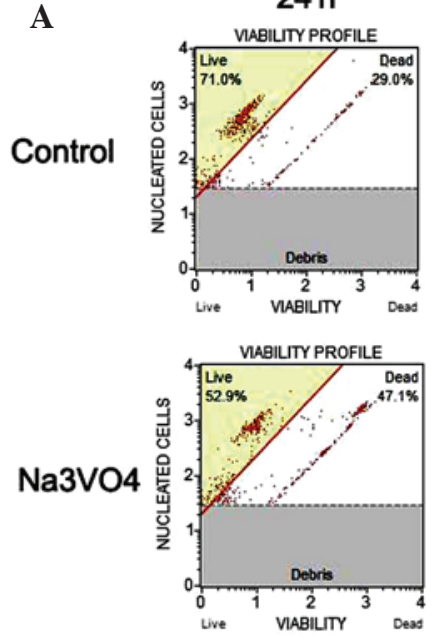

$48 \mathrm{~h}$

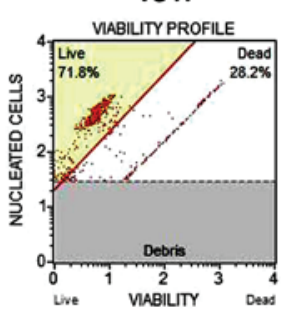

VABIUTY PROFILE

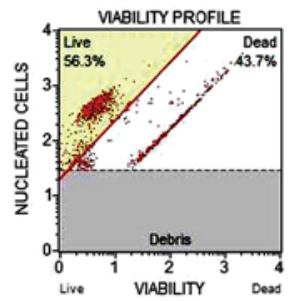

$72 \mathrm{~h}$
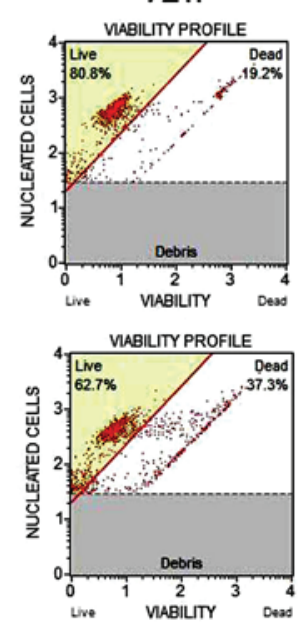

B

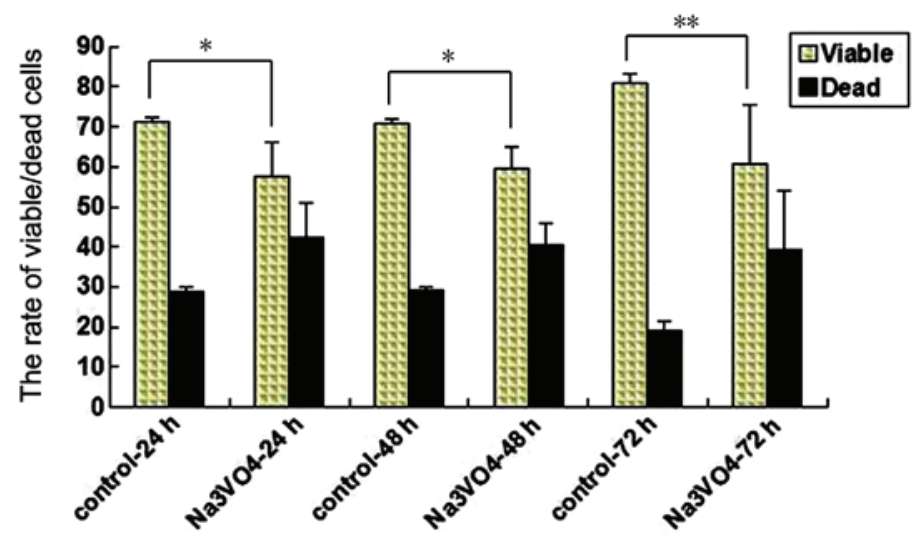

Figure 3. SOV reduces the percentage of viable cells. (A) Flow cytometry of SH-SY5Y cells in the control and SOV groups. The viable cells located in the top left and dead cells located in the lower right. (B) Bar graph to show the average percentage of viable cells and dead cells in the control and SOV groups ${ }^{*} \mathrm{P}<0.05$, *** $\mathrm{P}<0.01$. SOV, sodium orthovanadate $\left(\mathrm{Na}_{3} \mathrm{VO}_{4}\right)$.

$24 \mathrm{~h}$ of treatment with $5 \mu \mathrm{M} \mathrm{SOV}$, with a maximum reduction at $72 \mathrm{~h}$ (Fig. 1). This anti-proliferative effect occurred in a dose- and time-dependent manner at 10 and $50 \mu \mathrm{M}$ at 24,48 and $72 \mathrm{~h}$. These results indicate that SOV attenuates NB cell proliferation. Thus $5 \mu \mathrm{M}$ SOV was selected for use in further assays.

SOV induces apoptosis in SH-SY5Y cells. The early apoptotic cells were stained with Annexin V, and are observed in the right lower quadrant (Fig. 2A). The results showed that the apoptotic rates in the SOV group were $2.70 \pm 0.20,3.53 \pm 1.50$ and $7.93 \pm 1.07 \%$ respectively, at 24,48 and $72 \mathrm{~h}$, which were significantly higher than those in control group $(\mathrm{P}<0.05$, Fig. 2B). In addition, the apoptotic rates increased with time following SOV treatment, and reached a climax at $72 \mathrm{~h}$ (Fig. 2B, P<0.01). These results indicated that apoptosis was induced by SOV in SH-SY5Y cells.

SOV reduces the percentage of viable cells. Viable cells are located in the top left quadrant and dead cells are located in the lower right quadrant (Fig. 3A). After SOV treatment, the average percentages of viable cells were $57.59 \pm 8.72,59.47 \pm 5.36$ and $60.57 \pm 14.72 \%$ at 24,48 and $72 \mathrm{~h}$ respectively, while those in control group were $71.17 \pm 1.21,70.9 \pm 0.91$ and $80.98 \pm 2.30 \%$, respectively (Fig. 3B, $\mathrm{P}<0.05$ ). This suggested that $\mathrm{SOV}$ could reduce the percentage of viable cells, particularly at $72 \mathrm{~h}$ where they were reduced by $\sim 25.2 \%$ (Fig. $3 \mathrm{~B}, \mathrm{P}<0.05$ ).

SOV induces the accumulation of SH-SY5Y cells at the G2/M phase. As shown in Fig. 4A, the number of SH-SY5Y cells in the G0/G1 phase decreased, while those in the $\mathrm{S}$ and G2/M phase increased following SOV treatment. At $24 \mathrm{~h}$ after treatment, $45.48 \%$ of the SOV-treated SH-SY5Y cells were in the G0/G1 phase, $40.10 \%$ at $\mathrm{S}$ and $14.41 \%$ at $\mathrm{G} 2 / \mathrm{M}$ (Fig. 4B, $\mathrm{P}<0.05$ ). By comparison, $73.15 \%$ of the PBS-treated SH-SY5Y cells were at $\mathrm{G} 0 / \mathrm{G} 1,21.26 \%$ at $\mathrm{S}$ and $5.58 \%$ at $\mathrm{G} 2 / \mathrm{M}$ (Fig. $4 \mathrm{~B}, \mathrm{P}<0.05$ ). This trend was continued at later time points (Fig. 4B). This suggested that PIWIL2 is key in cell cycle regulation and that SOV induces accumulation of SH-SY5Y cells at the G2/M and $\mathrm{S}$ phase of the cell cycle.

SOV treatment inhibits the expression of PIWIL2 mRNA. RT-qPCR showed that the relative expression of PIWIL2 mRNA was $0.45 \pm 0.02$ following SOV treatment, which was lower than that in the control group (Fig. 5, P<0.05). The results indicated that SOV treatment suppressed the expression of PIWIL2 mRNA to a certain extent.

SOV reduces the expression of anti-apoptotic protein Bcl-2. It has been reported that knocking out the PIWIL2 gene in 
A
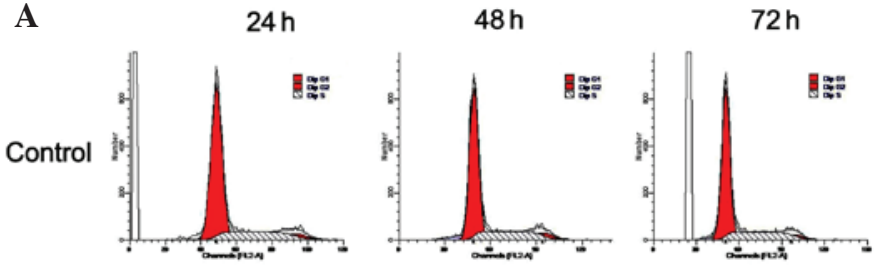

Na3VO4 \&ै)
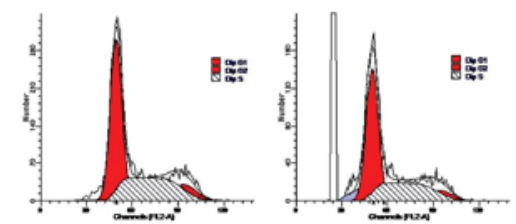

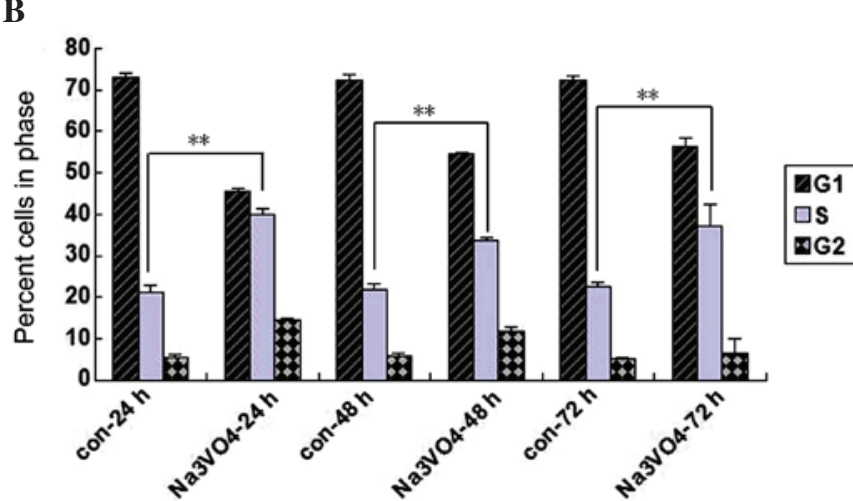

Figure 4. SOV induces G2/M accumulation in SH-SY5Y cells. (A) The representative images of distribution of stained SH-SY5Y cells in the control and SOV groups. (B) Bar graph of the average percent cells of G0/G1, S and G2/M phases in the control and SOV groups for SH-SY5Y cells respectively. ${ }^{* *} \mathrm{P}<0.01$. SOV, sodium orthovanadate $\left(\mathrm{Na}_{3} \mathrm{VO}_{4}\right)$.

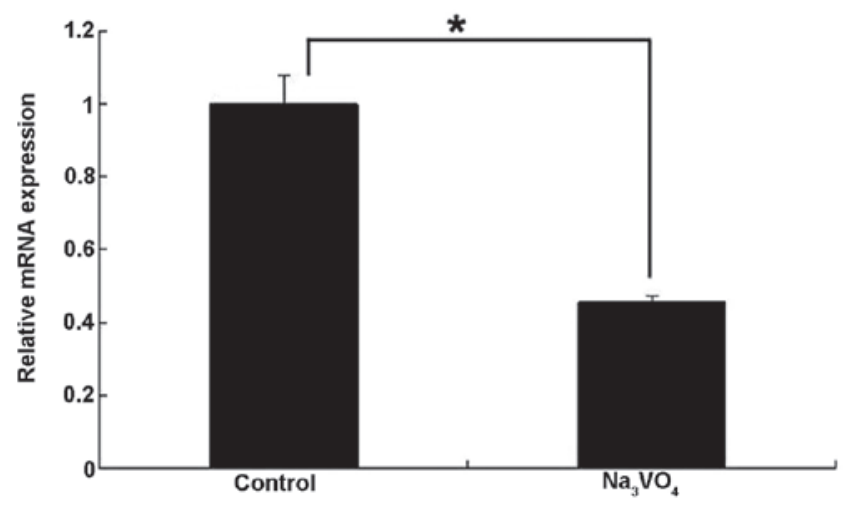

Figure 5. SOV inhibits the expression of PIWIL2 mRNA. Bar graph of the relative expression of PIWIL2 mRNA in the control and SOV groups $\left({ }^{*} \mathrm{P}<0.05\right)$. SOV, sodium orthovanadate $\left(\mathrm{Na}_{3} \mathrm{VO}_{4}\right)$.

SW620 and SW480 colon cancer cell lines inhibited cell proliferation, invasion and metastasis in vitro, and tumorigenicity in vivo (17). Western blot analysis was performed to determine whether PIWIL2 inhibition induces apoptosis in SH-SY5Y cells and whether Bcl-2 is involved. PIWIL2 expression in SH-SY5Y cells was inhibited by $5 \mu \mathrm{M}$ SOV. Following inhibition of PIWIL2 in SH-SY5Y cells, protein levels of PIWIL2 and $\mathrm{Bcl}-2$ were reduced (Fig. 6, $\mathrm{P}<0.05$ ). This indicates that SOV may induce apoptosis in SH-SY5Y cells in part by reducing the expression of the anti-apoptotic protein $\mathrm{Bcl}-2$.

\section{Discussion}

NBs of higher-grade are aggressive and have low cure rates even with combined modality treatments of radiation, chemotherapy and surgery (23). Understanding the molecular mechanism of this disease may aid in the development of future therapeutic strategies. Recent evidence has shown that PIWIL2 proteins are widely expressed in tumors and can regulate genes involved in apoptosis and proliferation (24), and SOV exhibited antineoplastic activity in a variety of human cancer cells (20). In addition, PIWIL2 has also been shown to act as an oncogene by inhibiting apoptosis and promoting proliferation via Stat3/ Bcl-XL signaling (24). The overexpression of PIWIL2 in certain cancers can cause cellular drug resistance, whereas silencing the
A

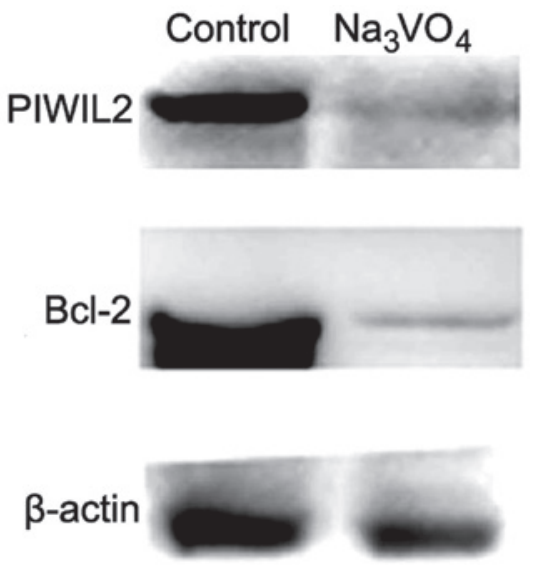

B

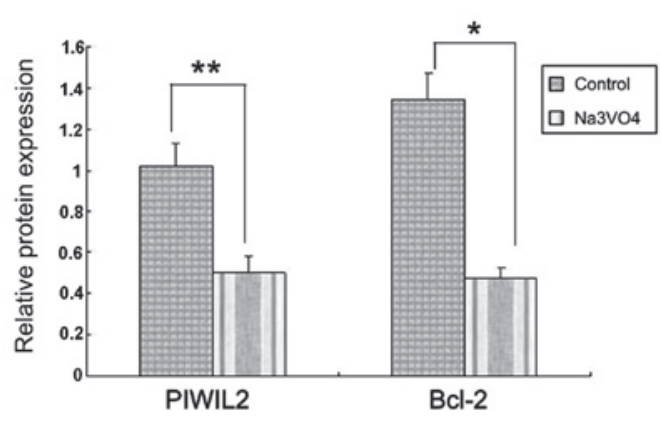

Figure 6. SOV reduces the expression of Bcl-2. (A) Western blot analysis of PIWIL2 and Bcl-2 proteins in SH-SY5Y cells. $\beta$-actin served as a loading control. (B) Bar graph shows the relative protein expression presented as the mean \pm standard deviation of the ratio of PIWIL2 or Bcl-2/ $\beta$-actin band intensity obtained by pooling the results from three independent experiments in $\mathrm{SH}-\mathrm{SY} 5 \mathrm{Y}$ cells respectively ( $\mathrm{P}<0.05$ and $\left.{ }^{* *} \mathrm{P}<0.01\right)$. SOV, sodium orthovanadate $\left(\mathrm{Na}_{3} \mathrm{VO}_{4}\right)$.

PIWIL2 gene can inhibit the expression of Stat3 and Bcl-XL, and induce ovarian cancer cell apoptosis (25). These reports indicated that the increase in the levels of PIWIL2 protein in cancer cells was one of the reasons for the reduction in sensitivity to chemotherapy and increasing chemo-resistance. For these reasons, this study aimed to determine whether PIWIL2 was also involved in NB carcinogenesis and whether SOV had an anti-proliferative effect in NB.

In the present study, the effect of different concentrations of SOV on cell proliferation was detected using an MTT assay, 
and the concentration of $5 \mu \mathrm{M}$ was selected for the follow-up tests, as cell activity decreased the most at this concentration $(\sim 30 \%)$, compared with the other concentrations. Higher concentrations resulted in a less marked decrease in activity, suggesting potential toxicity (Fig. 1). The results showed that the activity of SH-SY5Y cells reduced by $\sim 48 \%$ after treatment with $5 \mu \mathrm{M}$ SOV for $24 \mathrm{~h}$. While in HCC cells, after $72 \mathrm{~h}$ treatment with SOV, there was a significant difference in the cell viability index between control and cells treated with 15 or $30 \mu \mathrm{M}$ SOV $(\mathrm{P}<0.05)(18)$. Moreover, within the concentration range of $1-20 \mu \mathrm{M}$, SOV demonstrated a time and dose-dependent inhibition of autocrine growth of the A549 (lung), HTB44 (kidney) and DU145 (prostate) human carcinoma cell lines, as compared with the appropriate controls (20). The difference may be associated with varying cell type.

It was then demonstrated that SOV induced apoptosis of SH-SY5Y cells using the Annexin V/FITC Apoptosis Detection kit (Fig. 2), and reduced the percentage of viable cells using count and viability testing (Fig. 3). Similar results have also been reported in HCC, A549, HTB44, DU145, SN56 (cholinergic neuroblastoma) and H35-19 (rat hepatoma) cells $(18,20,26,27)$. In addition, Delwar et al (28) found that the combination of menadione and SOV $(17.5 \mu \mathrm{M}: 17.5 \mu \mathrm{M})$ eliminated and inhibited migration of detached A549 and DBTRG-05MG human glioma cells. The data contributed to the evaluation of SOV, its implications in invasiveness and metastasis, and its sensitivity to anticancer drugs.

Furthermore, the present study examined the underlying mechanism and found that it may be associated with the cell cycle and PIWIL2 inhibition. The present study demonstrated that SOV induced accumulation of SH-SY5Y cells at the G2/M and S phase of the cell cycle. Woo et al (29) showed that SOV caused G2/M phase cell cycle arrest in Chinese hamster ovary cells, and Klein et al (20) demonstrated that SOV could induce G2/M phase cell cycle arrest in all three selected HCC cell lines. The results of the present study were in accordance with their findings. In addition, the expression of PIWIL2 was investigated using RT-qPCR and western blot analysis in SH-SY5Y cells, and it was found that SOV inhibited the expression of PIWIL2 mRNA and protein. This phenomenon was accompanied by the reduction of Bcl-2. Therefore, it was speculated that SOV suppression of cell proliferation may occur via the induction of mitochondria-dependent apoptosis. Based on these findings, future studies in vivo may define the mechanism of PIWIL2 in the downregulation of Bcl-2.

In conclusion, to the best of our knowledge, the present study demonstrated for the first time that SOV induced the apoptosis of SH-SY5Y cells. Although the mechanism for inducing Bcl-2 downregulation remains to be determined, the results suggest that the underlying mechanisms may be, at least in part, due to SOV suppression of proliferation, and induction of mitochondria-dependent apoptosis and G2/M cell cycle arrest of SH-SY5Y cells. These findings demonstrated activities of SOV and supported its further evaluation as a treatment for human NB.

\section{Acknowledgements}

This study was supported by the National Natural Science Foundation of China (grant no. 30772215). The authors would like to thank the Experimental Technology Center, Department of Developmental Biology, Department of Pharmacology, and Department of Pathophysiology in the China Medical University.

\section{References}

1. Maris JM and Matthay KK: Molecular biology of neuroblastoma. J Clin Oncol 17: 2264-2279, 1999.

2. Maris JM,Hogarty MD, Bagatell R and Cohn SL: Neuroblastoma. Lancet 369: 2106-2120, 2007

3. Sharp SE, Gelfand MJ and Shulkin BL: Pediatrics: Diagnosis of neuroblastoma. Semin Nucl Med 41: 345-353, 2011.

4. Matthay KK, Villablanca JG, Seeger RC, Stram DO, Harris RE, Ramsay NK, Swift P, Shimada H, Black CT, Brodeur GM, et al: Treatment of high-risk neuroblastoma with intensive chemotherapy, radiotherapy, autologous bone marrow transplantation and 13-cis-retinoic acid. Children's Cancer group. N Engl J Med 341: 1165-1173, 1999.

5. Pearson AD, Pinkerton CR, Lewis IJ, Imeson J, Ellershaw C and Machin D; European Neuroblastoma Study Group, Children's Cancer and Leukaemia Group (CCLG formerly United Kingdom Children's Cancer Study Group): High-dose rapid and standard induction chemotherapy for patients aged over 1 year with stage 4 neuroblastoma: A randomised trial. Lancet Oncol 9: 247-256, 2008.

6. Zage PE, Kletzel M, Murray K, Marcus R, Castleberry R, Zhang Y, London WB and Kretschmar C; Children's Oncology Group: Outcomes of the POG 9340/9341/9342 trials for children with high-risk neuroblastoma: A report from the Children's Oncology Group. Pediatr Blood Cancer 51: 747-753, 2008.

7. Lau L, Tai D, Weitzman S, Grant R, Baruchel S and Malkin D: Factors influencing survival in children with recurrent neuroblastoma. J Pediatr Hematol Oncol 26: 227-232, 2004.

8. Laverdière C, Cheung NK, Kushner BH, Kramer K, Modak S, LaQuaglia MP, Wolden S, Ness KK, Gurney JG and Sklar CA: Long-term complications in survivors of advanced stage neuroblastoma. Pediatr Blood Cancer 45: 324-332, 2005.

9. Chen C, Liu J and Xu G: Overexpression of PIWI proteins in human stage III epithelial ovarian cancer with lymph node metastasis. Cancer Biomark 13: 315-321, 2013.

10. Sharma AK, Nelson MC, Brandt JE, Wessman M, Mahmud N, Weller KP and Hoffman R: Human CD34 (+) stem cells express the hiwi gene, a human homologue of the Drosophila gene piwi. Blood 97: 426-434, 2001.

11. Carmell MA, Girard A, van de Kant HJ, Bourc'his D, Bestor TH, de Rooij DG and Hannon GJ: MIWI2 is essential for spermatogenesis and repression of transposons in the mouse male germline. Dev Cell 12: 503-514, 2007.

12. Aravin A, Gaidatzis D, Pfeffer S, Lagos-Quintana M, Landgraf P, Iovino N, Morris P, Brownstein MJ, Kuramochi-Miyagawa S, Nakano T, et al: A novel class of small RNAs bind to MILI protein in mouse testes. Nature 442: 203-207, 2006.

13. Qiao D, Zeeman AM, Deng W, Looijenga LH and Lin H: Molecular characterization of hiwi, a human member of the piwi gene family whose overexpression is correlated to seminomas. Oncogene 21: 3988-3999, 2002.

14. Su C, Ren ZJ, Wang F, Liu M, Li X and Tang H: PIWIL4 regulates cervical cancer cell line growth and is involved in down-regulating the expression of p14ARF and p53. FEBS Lett 586: 1356-1362, 2012.

15. Liu C, Qu L, Dong B, Xing X, Ren T, Zeng Y, Jiang B, Meng L, Wu J and Shou C: Combined phenotype of 4 markers improves prognostic value of patients with colon cancer. Am J Med Sci 343: 295-302, 2012.

16. Li D, Sun X, Yan D, Huang J, Luo Q, Tang H and Peng Z: Piwil2 modulates the proliferation and metastasis of colon cancer via regulation of matrix metallopeptidase 9 transcriptional activity. Exp Biol Med (Maywood) 237: 1231-1240, 2012.

17. Korbecki J, Baranowska-Bosiacka I, Gutowska I and Chlubek D: Biochemical and medical importance of vanadium compounds. Acta Biochim Pol 59: 195-200, 2012.

18. Wu Y, Ma Y, Xu Z, Wang D, Zhao B, Pan H, Wang J, Xu D, Zhao X, Pan S, et al: Sodium orthovanadate inhibits growth of human hepatocellular carcinoma cells in vitro and in an orthotopic model in vivo. Cancer Lett 351: 108-116, 2014.

19. Ipsaro JJ, Haase AD, Knott SR, Joshua-Tor L and Hannon GJ: The structural biochemistry of Zucchini implicates it as a nuclease in piRNA biogenesis. Nature 491: 279-283, 2012. 
20. Klein A, Holko P, Ligeza J and Kordowiak AM: Sodium orthovanadate affects growth of some human epithelial cancercells (A549, HTB44, DU145). Folia Biol (Krakow) 56: 115-121, 2008.

21. Bradford MM: A rapid and sensitive method for the quantitation of microgram quantities of protein utilizing the principle of protein-dye binding. Anal Biochem 72: 248-254, 1976.

22. Dryer RL and Lata GF (eds): Experimental biochemistry. New York: Oxford University Press, New York, NY, pp346-347, 1989.

23. Maris JM: Recent advances in neuroblastoma. N Engl J Med 362: 2202-2211, 2010.

24. Lee JH, Schütte D, Wulf G, Füzesi L, Radzun HJ, Schweyer S, Engel W and Nayernia K: Stem-cell protein Piwil2 is widely expressed in tumors and inhibits apoptosis through activation of Stat3/Bcl-XL pathway. Hum Mol Genet 15: 201-211, 2006.

25. Wang QE, Han C, Milum K and Wani AA: Stem cell protein Piwil2 modulates chromatin modifications upon cisplatin treatment. Mutat Res 708: 59-68, 2011.
26. Suwalsky M, Fierro P, Villena F, Aguilar LF, Sotomayor CP, Jemiola-Rzeminska M, Strzalka K, Gul-Hinc S, Ronowska A and Szutowicz A: Human erythrocytes and neuroblastoma cells are in vitro affected by sodium orthovanadate. Biochim Biophys Acta 1818: 2260-2270, 2012.

27. Kordowiak AM, Klein A, Goc A and Dabroś W: Comparison of the effect of $\mathrm{VOSO} 4, \mathrm{Na} 3 \mathrm{VO} 4$ and $\mathrm{NaVO} 3$ on proliferation, viability and morphology of H35-19 rat hepatoma cell line. Pol J Pathol 58: 51-57, 2007.

28. Delwar ZM, Siden A, Cruz MH and Yakisich JS: Menadione: Sodium orthovanadate combination eliminates and inhibits migration of detached cancer cells. ISRN Pharmacol 2012: 307102, 2012.

29. Woo ES, Rice RL and Lazo JS: Cell cycle dependent subcellular distribution of Cdc25B subtypes. Oncogene 18: 2770-2776, 1999. 